\title{
Preoperative Factors Associated with Difficult Laparoscopic Cholecystectomy
}

\author{
Zaineb Tayyab ${ }^{1}$, Hassaan Ahmad ${ }^{2}$, Hajirah Khalid ${ }^{3 *}$, Hassan Mumtaz ${ }^{4}$, Syeda Ameera Nobia ${ }^{5}$, \\ Memoona Javed ${ }^{6}$, Shahzeb Habib ${ }^{7}$ and Aamir Ghazanfar ${ }^{8}$
}

${ }^{1}$ General Surgery, KRL Hospital, Islamabad, PAK

${ }^{2}$ Medicine, Holy Family Hospital, Rawalpindi, Lahore, PAK

${ }^{3}$ General Surgery, KRL Hospital, Islamabad, PAK

${ }^{4}$ Urology, Guys \& St. Thomas, Hospital, London, GBR, General Medicine, Surrey Docks, Health Center, London, GBR, Surgery, KRL Hospital, Islamabad, PAK

${ }^{5}$ General Surgery, KRL Hospital, Islamabad, PAK

${ }^{6}$ Surgery, KRL Hospital, Islamabad, PAK

${ }^{7}$ General Surgery, KRL Hospital, Islamabad, PAK

${ }^{8}$ Vascular Surgery, KRL Hospital, Islamabad, PAK

*Corresponding author: Hassan Mumtaz, Urology, Guys \& St. Thomas, Hospital, London, GBR, General Medicine, Surrey Docks,

Health Center, London

\begin{tabular}{l} 
ARTICLE INFO \\
\hline Received: 蔧 January 01, 2021 \\
Published: 幽 January 11, 2021
\end{tabular}

Citation: Zaineb T, Hassaan A, Hajirah K, Hassan M, Syeda Ameera N, et al., Preoperative Factors Associated with Difficult Laparoscopic Cholecystectomy. Biomed J Sci \& Tech Res 33(1)-2021. BJSTR. MS.ID.005349.

Keywords: Difficult Laparoscopic Cholecystectomy; Pre-operative Factors

\section{ABSTRACT}

Background: Laparoscopic cholecystectomy is the gold standard treatment for gallstones. Laparoscopic cholecystectomy provides improved cosmesis and improved patient satisfaction as compared with open cholecystectomy. Gall stones are commonly observed, and laparoscopic cholecystectomy has become the standard treatment for this disease.

Objective: To determine the frequency of difficult laparoscopic cholecystectomy (based on duration of surgery and conversion) and to identify pre- operative factors associated with it.

\section{Material \& Methods:}

a) Study Design: Cross sectional study

b) Setting: Department of surgery, KRL Hospital, Islamabad

c) Duration: 6 months i.e., from 1st September 2019 to 29 February 2020

d) Data collection: After meeting the inclusion criteria 100 patients were enrolled. Informed consent and demographic information were taken. Data regarding absence or presence of factors were collected and difficulty in laparoscopic cholecystectomy was noted. All the collected data was entered and analyzed on SPSS version 16.

Results: In our study the average age of the patients was $46.52 \pm 15.59$ years, average duration of surgery of the patients was $18.74 \pm 8.84$ minutes. Our 2 (2\%) patients needed conversion to open cholecystectomy for the treatment and difficult laparoscopic cholecystectomy, based on operative time, was noted in 30 (30\%) of the patients.

Conclusion: The difficult laparoscopic cholecystectomy observed in approximately one third of the patients. The clinical assessment is a useful method for the assessment of difficult laparoscopic cholecystectomy and for planning safe surgery pre-operatively. 


\section{Introduction}

Laparoscopic cholecystectomy is the gold standard treatment for gallstones. Preoperative estimation of difficulty level can help plan a safe surgery with minimal complications. Cases with anticipated higher degree of difficulty can be planned for open cholecystectomy or be referred to a more experienced surgeon [1]. Vivek and associates assessed difficulty level in creating pneumoperitoneum, getting to peritoneal cavity, adhesiolysis, distinguishing anatomical structures and removing the gall bladder. Age $>65$ years, male gender, recurrent attacks, history of previous abdominal surgery, deranged liver function tests and serum amylase levels and distended gall bladder with pericholecystic inflammation on ultrasonography, were identified to be some of the factors associated with difficult laparoscopic cholecystectomy in their study [2]. Previous history of acute cholecystitis, acute cholecystitis on admission, $>5$ recurrent attacks of pain that lasted more than 4 hours, diabetes mellitus, duration of symptoms longer than 36 months, gallbladder wall thickness $4 \mathrm{~mm}$, calculus size $>2 \mathrm{~cm}$ and presence of pericholecystic fluid collection on ultrasonography were significantly related to difficulty in laparoscopic cholecystectomy as concluded by Stanisic and collegues [3].

Few studies have assessed difficulty level based on deviation from the standard operative time [4-5]. Joshi at al predicted difficult laparoscopic cholecystectomy using a scoring system including history, clinical and sonographic parameters and predicted $78 \%$ of the cases to be easy and $22 \%$ as difficult, while, per-operatively, $74 \%$ of the cases were easy and $26 \%$ were not [4]. Although immense body of literature is present on this subject, but previous studies have shown variable results. Saber et al studied the operative difficulty in terms of bleeding and conversion to open cholecystectomy. Operative bleeding was seen in $7.84 \%$ and conversion to open surgery in $7.35 \%$ of patients, both of which were mainly associated with presence of acute cholecystitis (4.9\%), male gender $(10.2 \%)$, age $>50$ years, higher body mass index and peritoneal adhesion (8.62\%) [1]. Study done by Stanisic et al. showed difficulty based on conversion to open cholecystectomy in $2.7 \%$ of the patients [3].

Bourgouin et al. assessed difficulty level based on operative time and conversion to open surgery (4.3\%). According to operative time $35.2 \%$ of the cases were difficult. Statistically significant factors associated with difficulty were, age $>70$ years ( $47.3 \%$ ), male gender (67.8\%), Acute cholecystitis (69.6\%) and previous attack (18.2\%) [5]. Our aim is to determine the frequency of difficult laparoscopic cholecystectomy (based on duration of surgery and conversion) and to identify preoperative factors associated with it. Our study will contribute to the literature. Hence, with the help of this study we would identify the preoperative factors in our setting, which could lead to difficult laparoscopic cholecystectomy and help plan the safe surgery and post-operative care accordingly, minimizing the risk of complications.

\section{Materials and Methods}

This Cross-sectional study was done in the department of surgery, KRL Hospital, Islamabad. Duration of the study was six months, from 1st September 2019 to 29 February 2020. WHO calculator was used for sample size calculation. Population proportion of difficult laparoscopic cholecystectomy $=0.26$ [4]. Precision $=9 \%$, Confidence Interval $=95 \%$ Sample size calculated is 100 \& sampling technique used is consecutive non-probability sampling method. Inclusion criteria includes all laparoscopic cholecystectomy cases, aged 16-75 years, of both genders, operated at our hospital during the specified time. Whereas patients undergoing another procedure along with laparoscopic cholecystectomy in the same setting, all patients with gall stones undergoing elective open cholecystectomy were added in the exclusion criteria.

Data regarding absence or presence of factors were being studied, including: Age in groups, gender, Previous attack, Previous abdominal surgery, LFT, Serum Amylase, WBC in groups, Contracted/Distended Gallbladder on USG, Gall bladder wall thickness, Peri cholecystic fluid, Multiple stones and Cirrhosis on USG, was collected and difficulty in laparoscopic cholecystectomy was noted (as per operational definitions) on the Performa for all selected patients according to the sample size. Data analysis was done through SPSS version 16, mean and standard deviation was calculated for age and duration of surgery. All qualitative variables are presented in frequency and percentages. Chi square test was applied to test the association between difficult laparoscopic cholecystectomy and pre-operative risk. $p$ value was significant at $\leq 0.05$.

\section{Results}

In this study total 100 patients were enrolled. The mean age of the patients was $48.93 \pm 13$ years with minimum and maximum ages of $26 \& 75$ years, respectively. Whereas the average duration of surgery was $21.53 \pm 19.26$ minutes with minimum and maximum duration of $6 \& 150$ minutes, respectively (Table 1). In our study $2(2 \%)$ patients were converted to open laparoscopic cholecystectomy for the treatment. According to our, study difficult laparoscopic cholecystectomy was noted in 31 (31\%) patients (Table 2). The study results showed that age $>65$ years was noted in $18(18 \%)$ patients, 35 (35\%) patients were male and patients having previous attack were 50 (50\%). Whereas patients having previous abdominal surgery were 25 (25\%), murphy signs were noted in $22(22 \%)$ patients and deranged LFTs were found in 22 $(22 \%)$ patients. According to this study the elevated serum amylase was noted in $8(8 \%)$ patients, WBC>11000 was found in $17(17 \%)$ patients and contracted gall bladder was noted in 29 (29\%) patients. 
Table 1: Summary statistics of age (years) \& duration of surgery (minutes).

\begin{tabular}{|c|c|c|}
\hline Age: & $\mathbf{n}$ & $\mathbf{1 0 0}$ \\
\hline & Mean & 48.93 \\
\hline & Standard Deviation & 13 \\
\hline & Minimum & 26 \\
\hline $\begin{array}{c}\text { Duration of surgery } \\
\text { (minutes) }\end{array}$ & Maximum & 75 \\
\hline & Mean & 21.53 \\
\hline & Minimum & 19.26 \\
\hline & Maximum & 6 \\
\hline
\end{tabular}

Table 2: Frequency distribution of conversion to laparoscopic cholecystectomy \& difficult laparoscopic cholecystectomy.

\begin{tabular}{|c|c|c|c|}
\hline & & Frequency & Percent \\
\hline \multirow{2}{*}{$\begin{array}{c}\text { Conversion to } \\
\text { open laparoscopic } \\
\text { cholecystectomy }\end{array}$} & Yes & 2 & $2 \%$ \\
\cline { 2 - 4 } & No & 98 & $98 \%$ \\
\hline \multirow{2}{\text{Difficultlaparoscopic}}{\begin{tabular}{c} 
cholecystectomy \\
\cline { 2 - 4 }
\end{tabular}} & Yes & 31 & $31 \%$ \\
\cline { 2 - 4 } & No & 69 & $69 \%$ \\
\hline
\end{tabular}

Table 3: Frequency distribution of pre-operative risk factors.

\begin{tabular}{|c|c|c|c|}
\hline & & Frequency & Percent \\
\hline \multirow{2}{*}{ Age >65: } & Yes & 18 & $18 \%$ \\
\hline & No & 82 & $82 \%$ \\
\hline \multirow{2}{*}{ Male: } & Yes & 35 & $35 \%$ \\
\hline & No & 65 & $65 \%$ \\
\hline \multirow{2}{*}{ Previous Attack: } & Yes & 50 & $50 \%$ \\
\hline & No & 50 & $50 \%$ \\
\hline \multirow{2}{*}{$\begin{array}{l}\text { Previous Abdominal } \\
\text { Surgery: }\end{array}$} & Yes & 25 & $25 \%$ \\
\hline & No & 75 & $75 \%$ \\
\hline \multirow{2}{*}{ Murphy Sign: } & Yes & 22 & $22 \%$ \\
\hline & No & 78 & $78 \%$ \\
\hline \multirow{2}{*}{ Deranged LFT's: } & Yes & 22 & $22 \%$ \\
\hline & No & 78 & $78 \%$ \\
\hline \multirow{2}{*}{ Elevated Seum Amylase: } & Yes & 8 & $8 \%$ \\
\hline & No & 92 & $92 \%$ \\
\hline \multirow{2}{*}{ WBC >11000: } & Yes & 17 & $17 \%$ \\
\hline & No & 83 & $83 \%$ \\
\hline \multirow{2}{*}{ Contracted gall bladder: } & Yes & 29 & $29 \%$ \\
\hline & No & 71 & $71 \%$ \\
\hline \multirow{2}{*}{ Gallbladder wall thickness } & Yes & 25 & $25 \%$ \\
\hline & No & 75 & $75 \%$ \\
\hline \multirow{2}{*}{ Pericholecystic fluid } & Yes & 12 & $12 \%$ \\
\hline & No & 88 & $88 \%$ \\
\hline \multirow{2}{*}{ Multiple stones } & Yes & 86 & $86 \%$ \\
\hline & No & 14 & $14 \%$ \\
\hline
\end{tabular}

The study results showed that the gall bladder wall thickness was found in 25 (25\%) patients, pericholecystic fluid found in $12(12 \%)$ patients and multiple stones were noted in $86(86 \%)$ patients (Table 3). According to this study, patients having age $>65$ years the difficult laparoscopic cholecystectomy is found in $7(38.9 \%)$ patients and patients having age $<65$ years the difficult laparoscopic cholecystectomy is noted in 24 (29.3\%) patients ( $p$-value=0.424). Similarly, among male patients the difficult laparoscopic cholecystectomy found in 13 (37.1\%) patients ( $p$-value=0.330). Patients having previous attack the difficult laparoscopic cholecystectomy found in 24 (48\%) patients and patients with no previous attack the difficult laparoscopic cholecystectomy noted in $7(14 \%)$ patients (p-value<0.001). Similarly, among patients having previous abdominal surgery the difficult laparoscopic cholecystectomy found in 9 (36\%) patients and patients with no previous abdominal surgery the difficult laparoscopic cholecystectomy noted in 22 (29.3\%) patients (p-value $=0.533)$.

Among patients with murphy signs the difficult laparoscopic cholecystectomy found in 13 (59.1\%) patients and patients without murphy signs the difficult laparoscopic cholecystectomy noted in $18(23.1 \%)$ patients ( $p$-value=0.001). Similarly, among patients having deranged LFTs the difficult laparoscopic cholecystectomy found in 11 (50.0\%) patients and patients without deranged LFTs the difficult laparoscopic cholecystectomy noted in 20 (25.6\%) patients ( $p$-value $=0.002$ ). The study shows that among patients with elevated serum amylase the difficult laparoscopic cholecystectomy found in $7(87.5 \%)$ patients and patients with no elevated serum amylase the difficult laparoscopic cholecystectomy noted in 24 (26.1\%) patients ( $\mathrm{p}$-value $<0.001)$. Similarly, among patients having WBC $>11000$ the difficult laparoscopic cholecystectomy found in $11(64.7 \%)$ patients and patients with $\mathrm{WBC}<11000$ the difficult laparoscopic cholecystectomy noted in 24 (26.1\%) patients ( $\mathrm{p}$-value $=0.001)$.

Whereas in patients with contracted gall bladder the difficult laparoscopic cholecystectomy found in 18 (62.1\%) patients and patients with no contracted gall bladder stones the difficult laparoscopic cholecystectomy noted in 13(18.3\%) patients ( $p$-value $<0.001)$. Similarly, among patients having gall bladder with thickness the difficult laparoscopic cholecystectomy found in $18(72 \%)$ patients and patients with no gall bladder thickness the difficult laparoscopic cholecystectomy noted in 13 (17.3\%) patients ( $p$-value $=<0.001$ ). According to this study among patients with peri cholecystic fluid the difficult laparoscopic cholecystectomy found in $8(66.7 \%)$ patients and patients without peri cholecystic fluid the difficult laparoscopic cholecystectomy noted in 23 (26.1\%) patients ( $\mathrm{p}$-value=0.004). Similarly, among patients with multiple stones the difficult laparoscopic cholecystectomy found in $30(34.9 \%)$ patients and patients with no multiple stones the difficult laparoscopic cholecystectomy noted in 1 (7.1\%) patient ( $p$-value=0.037). The study results showed that the out of 5 patients of cirrhosis the difficult laparoscopic cholecystectomy was observed in $1(20 \%)$ patient. This difference was statistically insignificant i.e. $p$-value $=0.585$ (Table 4 ). 
Table 4: Comparison of pre-operative risk factors.

\begin{tabular}{|c|c|c|c|c|c|}
\hline & & $\begin{array}{l}\text { Difficulty laparoscopic } \\
\text { cholecystectomy }\end{array}$ & $\begin{array}{l}\text { Difficulty laparoscopic } \\
\text { cholecystectomy }\end{array}$ & Total & P Value \\
\hline & & YES & No & & \\
\hline \multirow{2}{*}{ Age >65: } & Yes & 7 (38.9\%) & $11(61.1 \%)$ & $18(100 \%)$ & \\
\hline & No & $24(29.3 \%)$ & $58(70.7 \%)$ & $82(100 \%)$ & 0.424 \\
\hline \multirow[t]{2}{*}{ Male: } & Yes & $13(37.1 \%)$ & $22(62.9 \%)$ & $35(100 \%)$ & \\
\hline & No & $18(27.7 \%)$ & $47(72.3 \%)$ & $65(100 \%)$ & 0.33 \\
\hline \multirow[t]{2}{*}{ Previous Attack: } & Yes & $24(48 \%)$ & $26(52 \%)$ & $50(100 \%)$ & \\
\hline & No & $7(14 \%)$ & $43(86 \%)$ & $50(100 \%)$ & $<0.001$ \\
\hline \multirow[t]{2}{*}{ Previous Abdominal Surgery: } & Yes & $9(36 \%)$ & $16(64 \%)$ & $25(100 \%)$ & \\
\hline & No & $22(29.3 \%)$ & $53(70.7 \%)$ & $75(100 \%)$ & 0.533 \\
\hline \multirow[t]{2}{*}{ Murphy Sign: } & Yes & 13 (59.1\%) & $9(40.9 \%)$ & $22(100 \%)$ & \\
\hline & No & $18(23.1 \%)$ & $60(76.9 \%)$ & $78(100 \%)$ & 0.001 \\
\hline \multirow[t]{2}{*}{ Deranged LFT's: } & Yes & $11(50 \%)$ & $11(50 \%)$ & $22(100 \%)$ & \\
\hline & No & $20(25.6 \%)$ & $58(74.4 \%)$ & $78(100 \%)$ & 0.029 \\
\hline \multirow[t]{2}{*}{ Elevated Seum Amylase: } & Yes & 7 (87.5\%) & $1(12.5 \%)$ & $8(100 \%)$ & \\
\hline & No & $24(26.1 \%)$ & $68(73.9 \%)$ & $92(100 \%)$ & $<0.001$ \\
\hline \multirow[t]{2}{*}{ WBC > 11000: } & Yes & $11(64.7 \%)$ & $6(35.3 \%)$ & $17(100 \%)$ & \\
\hline & No & $20(24.1 \%)$ & $63(75.9 \%)$ & $83(100 \%)$ & 0.001 \\
\hline \multirow[t]{2}{*}{ Contracted gall bladder: } & Yes & $18(62.1 \%)$ & $11(37.9 \%)$ & $29(100 \%)$ & \\
\hline & No & $13(18.3 \%)$ & $58(81.7 \%)$ & $71(100 \%)$ & $<0.001$ \\
\hline \multirow[t]{2}{*}{ Gallbladder wall thickness } & Yes & $18(72 \%)$ & $7(28 \%)$ & $25(100 \%)$ & \\
\hline & No & $13(17.3 \%)$ & $62(82.7 \%)$ & $75(100 \%)$ & $<0.001$ \\
\hline \multirow[t]{2}{*}{ Pericholecystic fluid } & Yes & $8(66.7 \%)$ & $4(33.3 \%)$ & $12(100 \%)$ & \\
\hline & No & $23(26.1 \%)$ & $65(73.9 \%)$ & $88(100 \%)$ & 0.004 \\
\hline \multirow[t]{2}{*}{ Multiple stones } & Yes & $30(34.9 \%)$ & $56(65.1 \%)$ & $86(100 \%)$ & \\
\hline & No & $1(7.1 \%)$ & $13(92.9 \%)$ & $14(100 \%)$ & 0.037 \\
\hline \multirow[t]{2}{*}{ Cirrhosis } & Yes & $1(20 \%)$ & $4(80 \%)$ & $5(100 \%)$ & \\
\hline & No & $30(31.6 \%)$ & $65(68.4 \%)$ & $95(100 \%)$ & 0.585 \\
\hline
\end{tabular}

\section{Discussion}

Laparoscopic cholecystectomybeingthegoldstandard treatment of symptomatic cholelithiasis preoperative prediction of the risk of conversion is an important aspect of planning laparoscopic surgery. It is important to predict difficult laparoscopic cholecystectomy preoperatively so that senior surgeons can be requested to be present during surgery rather than less experienced junior surgeon prolonging the surgery which may lead to intraoperative complications. In preoperatively predicted to be conversion, early decision of conversion can be made so as to avoid unnecessarily prolonging the surgery and to prevent complications [6]. In this study the frequency of difficult laparoscopic cholecystectomy was noted in 30(30\%) cases. Ravindra Nidoni et al. [6] carried out a study on predicting difficult laparoscopic cholecystectomy based on clinicoradiological assessment. The author resulted that out of 180 patients included in this study 126 (70\%) were easy, 44 (24.44\%) were difficult and $3(5.56 \%)$ patients required conversion to open cholecystectomy.
The overall conversion rate was $5.6 \%$. Thyagarajan $\mathrm{M}$ et al. found a conversion rate of as high as $34 \%$ in cases with history of previous attacks of acute cholecystitis [7]. Bourgouin et al. [5] assessed difficulty level based on operative time and conversion to open surgery (4.3\%). According to operative time $35.2 \%$ of the cases were difficult. S Kumar et al. conducted a study which included 536 patients who underwent laparoscopic cholecystectomy [8]. The Overall conversion rate in their study was $7.81 \%$. Sharma SK et al conducted a study on 200 patients undergoing laparoscopic cholecystectomy at Kathmandu medical college [9]. The conversion rate in their study was $4 \%$. In our study the age, gender, previous abdominal surgery, multiple stone and cirrhosis are not found to be associated with the difficulty laparoscopic cholecystectomy or conversion to open cholecystectomy. Whereas previous attack, murphy signs, deranged LFTs, elevated serum amylase, WBC $>11000$, contracted gall bladder, gall bladder with thickness and peri cholecystic fluid are found to be associated with the difficulty laparoscopic cholecystectomy or conversion to open cholecystectomy. 
Some of the studies are discussed below showing the results in favor of our study as. Ravindra Nidoni et al. [6] showed that the total leukocyte count $>11000$, more than 2 previous attacks of cholecystitis, gall bladder wall thickness of $>3 \mathrm{~mm}$ and Pericholecystic collection were all statistically significant for predicting the difficult laparoscopic cholecystectomy and its conversion. Sanabria et al. found in their study of 628 patients that patients with multiple attacks (ten or more) were significantly associated with conversion [10]. Reported in a study of 300 patients assessing 24 variables for conversion that patients with history of acute chole cystitis within the last 3 weeks were at increased risk of conversion [11]. Many studies have identified raised WBC as a risk factor for predicting conversion [11-14]. Gall bladder wall thickness has been identified as a risk factor for conversion in many of the studies. The thickness of gall bladder associated with conversion varies from study to study. It was 3mm [15-16], $4 \mathrm{~mm}$ [17]. While in most of the studies age was considered as a risk factor for conversion $[12,13,15,17,18,19]$.

May be the reason is that they use some other value of age for cut off. Our study and some other authors did not notice age to be associated with conversion rate [20-21]. Male sex as an independent risk for conversion is controversial. Few series have shown it to be an independent risk factor [10,16,17,20,22-24]. However, like our study findings Liu et al. did not notice sex to be associated with conversion [18]. Atul Kumar Gupta et al. [25] concluded in their study that the clinical predictors are most reliable factors. Use of good clinical judgement regarding possibility of and likely difficulty along with understanding of available resources is important in making decision in each case. According to Bourgouin et al. the significant factors associated with difficulty were, age $>70$ years (47.3\%), male gender (67.8\%), Acute cholecystitis (69.6\%) and previous attack (18.2\%) [5].

\section{Conclusion}

The difficult laparoscopic cholecystectomy was observed in approximately one third of the patients and the previous attack, murphy's sign, deranged LFTs, elevated serum amylase, WBC $>11000$, contracted gall bladder, gall bladder with thickness $>3 \mathrm{~mm}$ and pericholecystic fluid were the factors associated with difficult laparoscopic cholecystectomy or conversion to open cholecystectomy. Hence, the clinical assessment is a useful method for the assessment of difficult laparoscopic cholecystectomy.

\section{References}

1. Saber A, Abu Elela ST, Shaalan KM, Al Masry AR (2015) Preoperative Prediction of the Difficulty of Laparoscopic Cholecystectomy. J Surg Surgical Res 1(1): 015-018.

2. Vivek MAKM, Augustine AJ, Rao RA (2014) comprehensive predictive scoring method for difficult laparoscopic cholecystectomy. Journal of minimal access surgery 10(2): 62.

3. Stanisic V, Milicevic M, Kocev N, Stojanovic M, Vlaovic D, et al. (2014) Prediction of difficulties in laparoscopic cholecystectomy on the base of routinely available parameters in a smaller regional hospital. Eur Rev Med Pharmacol Sci 18(8): 120-411.

4. Joshi MR, Bohara TP, Rupakheti S, Parajuli A, Shrestha DK, et al. (2015) Pre operative Prediction of Difficult Laparoscopic Cholecystectomy. Journal of the Nepal Medical Association 53(200): 221-226.

5. Bourgouin S, Mancini J, Monchal T, Calvary R, Bordes J, et al. (2016) How to predict difficult laparoscopic cholecystectomy? Proposal for a simple preoperative scoring system. The American journal of surgery 212(5): 873-881.

6. Nidoni R, Udachan TV, Sasnur P, Baloorkar R, Sindgikar V, et al. (2015) Predicting difficult laparoscopic cholecystectomy based on clinicoradiological assessment. Journal of clinical and diagnostic research: JCDR 9(12): PC09.

7. Thyagarajan M, Singh B, Thangasamy A, Rajasekar S (2017) Risk factors influencing conversion of laparoscopic cholecystectomy to open cholecystectomy. International Surgery Journal 4(10): 3354-3357.

8. Kumar S, Tiwary S, Agrawal N, Prasanna G, Khanna R, et al. (2008) Predictive factors for difficult surgery in laparoscopic cholecystectomy for chronic cholecystitis. The internal journal of surgery 6(2).

9. Sharma S, Thapa P, Pandey A, Kayastha B, Poudyal S, et al. (2006) Predicting difficulties during laparoscopic cholecystectomy by preoperative ultrasound. Kathmandu university medical journal (KUMJ) 5(17): 8-11.

10. Sanabria JR, Gallinger S, Croxford R, Strasberg SM (1994) Risk factors in elective laparoscopic cholecystectomy for conversion to open cholecystectomy. Journal of the American College of Surgeons 179(6): 696-704.

11. Schrenk P, Woisetschläger R, Wayand W (1995) Laparoscopic cholecystectomy. Surgical endoscopy 9(1): 25-28.

12. Brodsky A, Matter I, Sabo E, Cohen A, Abrahamson J, et al. (2000) Laparoscopic cholecystectomy for acute cholecystitis: can the need for conversion and the probability of complications be predicted? Surgical endoscopy 14(8):755-760.

13. Bedirli A, Sakrak O, Sözüer EM, Kerek M, Güler I (2001) Factors effecting the complications in the natural history of acute cholecystitis. Hepato gastroenterology 48(41): 1275-1278.

14. Ibrahim S, Hean TK, Ho LS, Ravintharan T, Chye TN, et al. (2006) Risk factors for conversion to open surgery in patients undergoing laparoscopic cholecystectomy. World journal of surgery 30(9): 16981704.

15. Fried GM, Barkun JS, Sigman HH, Joseph L, Clas D, et al. (1994) Factors determining conversion to laparotomy in patients undergoing laparoscopic cholecystectomy. The American journal of surgery 167(1): 35-41.

16. Nachnani J, Supe A (2005) Pre operative prediction of difficult laparoscopic c oscopic c oscopic cholecystectomy using clinical and ultrasonographic parameters. Indian J Gastroenterol pp. 16-18.

17. Jansen S, Jorgensen J, Caplehorn J, HuntD (1997) Preoperative ultrasound to predict conversion in laparoscopic cholecystectomy 7(2):121-123.

18. Jansen S, Jorgensen J, Caplehorn J, Hunt D (1997) Preoperative ultrasound to predict conversion in laparoscopic cholecystectomy. Surgical laparoscopy \& endoscopy 7(2): 121-123.

19. Liu Cl, Fan St, Lai EC, Lo Cm, Chu KM (1996) Factors affecting conversion of laparoscopic cholecystectomy to open surgery. Archives of surgery 131(1): 98-101.

20. Brunt L, Quasebarth M, Dunnegan D, Soper N (2001) Outcomes analysis of laparoscopic cholecystectomy in the extremely elderly. Surgical endoscopy 15(7): 700-705.

21. Hutchinson C, Traverso L, Lee F (1994) Laparoscopic cholecystectomy. Surgical endoscopy 8(8): 875878. 
22. Teixeira J, Saraiva A, Cabral AC, Barros H, Reis J, et al. (2000) Conversion factors in laparoscopic cholecystectomy for acute cholecystitis. Hepato gastroenterology 47(33): 626-630.

23. Zisman E, Negri M, Halpern Z, Lin G (1996) Is male gender a risk factor for conversion of laparoscopic into open cholecystectomy? Surgical endoscopy 10(9): 892-894.

24. Sikora S, Kumar A, Saxena R, Kapoor V, Kaushik S (1995) Laparoscopic cholecystectomy-can conversion be predicted? World journal of surgery 19(6): 858-860.

\section{ISSN: 2574-1241}

DOI: $10.26717 /$ BJSTR.2021.33.005349

Hajirah Khalid. Biomed J Sci \& Tech Res

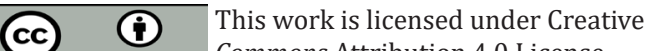
Commons Attribution 4.0 License

Submission Link: https://biomedres.us/submit-manuscript.php
25. Yol S, Kartal A, Vatansev C, Aksoy F, Toy H (2006) Sex as a factor in conversion from laparoscopic cholecystectomy to open surgery. JSLS: Journal of the Society of Laparoendoscopic Surgeons 10(3): 359-363.

26. Gupta AK, Shiwach N, Gupta S, Gupta S, Goel A, et al. (2018) Predicting difficult laparoscopic cholecystectomy. International Surgery Journal 5(3): 1094-1099.

$\begin{array}{ll}\text { BIOMEDICAL } & \text { Assets of Publishing with us } \\ \text { RESEARCHES } & \text { - Global archiving of articles } \\ \text { - Immediate, unrestricted online access } & \text { - Rigorous Peer Review Process } \\ & \text { - Authors Retain Copyrights }\end{array}$

